\title{
Histopathological changes and immunosuppression induce by diazepam in mice
}

A. H. Ali

Coll. of Vet. Med. -Univ. of Al-Qadisiya
KH. Zinad

Coll. of Vet. Med.-Univ. of Baghdad

\begin{abstract}
In order to investigate the histological changes and immunosuppression effects of diazepam in mice, forty white mice of both sexes were divided into four groups equally. $1^{\text {st }}$ group was immunized twice with pasturella multocida (bacterines) with two weeks intervals. $2^{\text {nd }}$ group was immunized as in the $1^{\text {st }}$ group and at same time administrated orally with $0.6 \mathrm{mg} / \mathrm{kg} \mathrm{b} . \mathrm{w}$ of diazepam daily for 8 weeks. $3^{\text {rd }}$ group was administrated with diazepam as in the $2^{\text {nd }}$ group while 4th group was served as control negative group. Immunological examination revealed that the diazepam inducing depresses of the both arms of immune response, the cell mediated immunity and humeral immunity as comparing with vaccinated non-treatment animals. The pathological examination revealed that the diazepam induced large multiple granulomatous liver lesions consist form aggregation mononuclear cells particularly macrophages and lymphocytes. In addition, section of kidney showed marked inflammatory cells infiltration particularly mononuclear cells and neutrophils in the interstitial tissues was seen. In spleen there was congestion of blood vessels with mononuclear cells in their lumen and depletion of white pulp as well as proliferation of megakaryocytes, in addition to gliosis in the brain parenchyma was seen. The immunized animals showed mild pathological changes characterized by aggregation mononuclear cells around central vein in addition to proliferation of kupffer cells, Spleen show proliferation of lymphocytes in the periartiriolar sheath as well as protein aqueous materials deposition around white pulp. We concluded that diazepam induced Histological changes in the internal organs of mice and stimulated the immune response diminished its toxic effects.
\end{abstract}

Key words: Diazepam, Histological, Immune suppression.

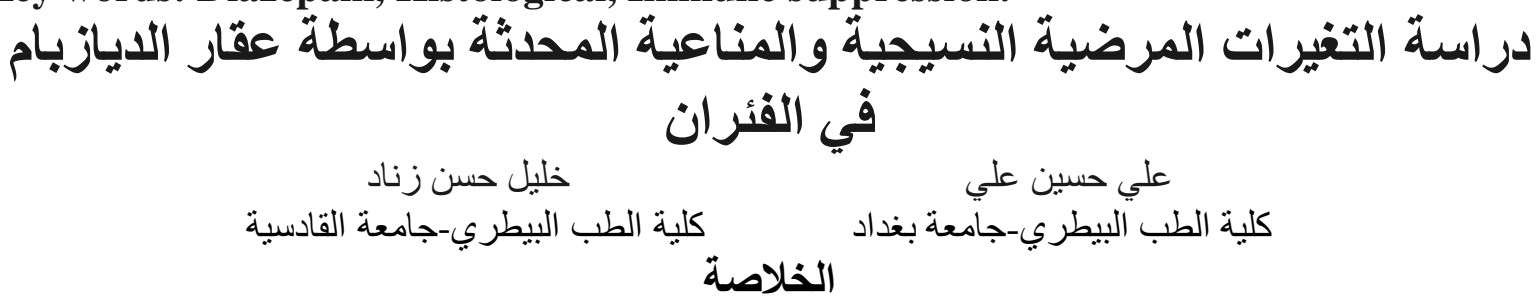

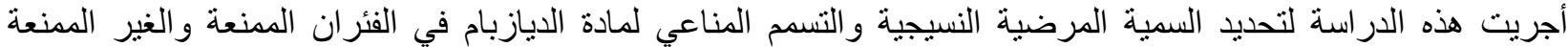

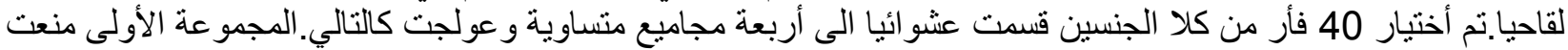

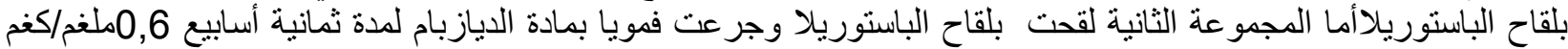

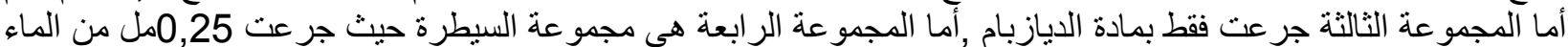

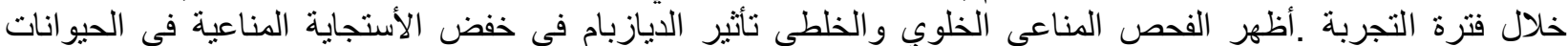

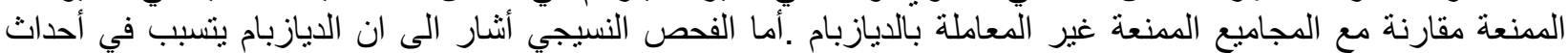

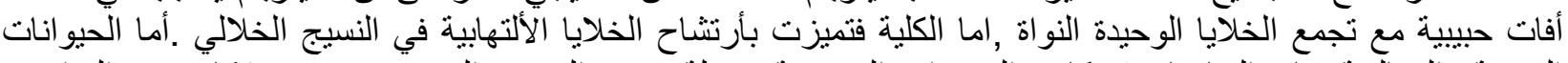

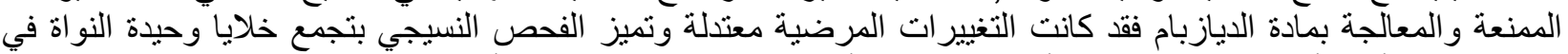

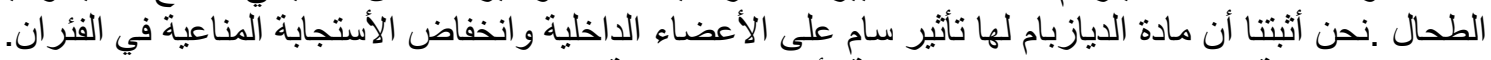
الكلمات المفتاحية: الديازبام. التغييرات النسيجية. أنخفاض النيام المناعة.

\section{Introduction}

Diazepam is a member of a group of medications that belong to a group known as benzodiazepines. It is commonly used to treat anxiety, panic attacks, insomnia, seizures (including status epileptics), muscle spasms (such as in tetanus cases), restless legs syndrome, alcohol withdrawal, benzodiazepine withdrawal, opiate withdrawal syndrome and Meniere's disease (1). It may also be used before certain medical procedures (such as endoscopies) to reduce tension and anxiety, and in some surgical procedures to induce amnesia (2).It 
possesses anxiolytic, anticonvulsant, hypnotic, sedative, skeletal muscle relaxant, and amnestic properties (3). All benzodiazepines, including diazepam, effect on peripheral benzodiazepine receptor sites (PBR) or translocation protein receptor (TSPO) (4). Evidence for a direct immunomodulatory action for BZD emerged from recent studies demonstrating the presence of(TSPO) on immune/inflammatory cells (5). Diazepam overdose causes many problems in paradoxical side effects can occur, including nervousness, irritability, excitement, worsening of seizures, insomnia, muscle cramps and in some cases, rage . These adverse reactions are more likely to occur in children, the elderly, and individuals with a history of drug or alcohol abuse and or aggression(6). Diazepam may increase, in some people, the propensity toward selfharming behaviors and, in extreme cases, may provoke suicidal tendencies or acts. Patients with severe attacks of apnea during sleep may suffer respiratory depression (hypoventilation), leading to respiratory arrest and death (7). Acute hepatic injury may be caused by a direct toxic effect of the drug or its metabolites on the hepatocyte, producing a predictable dose-dependent effect, or by idiosyncratic drug reactions, which occur unpredictably in a small number of cats exposed to a particular drug such as diazepam (8).

\section{Materials and methods}

Diazepam using in water as a solvent, diazepam has an $0.6 \mathrm{mg} \backslash \mathrm{kg}$ b.w for white mice (8). Forty white mice of 7-8 weeks in age, supplied from animal house were used in this study the animals were divided into four each groups (10mice) and was treated as following: G1,was immunized with pasturellamultocida (bacterin), two doses, with two weeks intervals. G2,was immunized as in $1^{\text {st }}$ group and at the same time it was given daily diazepam, via oral route $0.6 \mathrm{mglkg}$, b.w for 8 weeks. G3, was administrated with diazepam as in $2^{\text {nd }}$ group. $\mathrm{G} 4$, was administrated daily with $0.3 \mathrm{ml}$ of sterile normal saline orally for 8 weeks and it was served as control negative group.

\section{Results}

\section{Immunological examination}

Skin test: At 24 hrs. post testing, the results showed that the mean values of skin thickness against bacterin was high in $1^{\text {st }}$ group $(0.94 \pm 0.01)$ as comparing with $2^{\text {th }}$ group $(0.25 \pm 0.01)$ and these values were decrease at $48 \mathrm{hr}$ post-examination in the $1^{\text {st }}$ group $(0.82 \pm 0.01), \quad, 2^{\text {nd }}$ group $(0.12 \pm 0.01)$. (table1).

Table (1) values skin test in immunized groups at 24and 48 hours. (measured in mm).

\begin{tabular}{|c|l|c|c|}
\hline Group & Group & $\begin{array}{l}24 \text { hmean } \\
\text { SE }\end{array}$ & $\begin{array}{c}48 \text { hmean } \\
S E\end{array}$ \\
\hline 1 & $\begin{array}{l}\text { pasturella } \\
\text { vaccine }\end{array}$ & $\begin{array}{c}0.94 \pm 0.01 \\
\mathrm{Ab}\end{array}$ & $\begin{array}{c}0.82 \pm 0.01 \\
\mathrm{Ba}\end{array}$ \\
\hline 2 & $\begin{array}{l}\text { diazepam } \\
\text { +pasturell } \\
\text { a vaccine }\end{array}$ & $\begin{array}{c}0.25 \pm 0.01 \\
\mathrm{Ad}\end{array}$ & $\begin{array}{c}0.12 \pm 0.01 \\
\mathrm{Bd}\end{array}$ \\
\hline
\end{tabular}

L.S.D $=0.16$

The results of passive haemagglutination examination in the 2 weeks revealed that the serum Abs titers in $1^{\text {st }}$ group was (307.20 \pm 86.82$)$ higher than in $2^{\text {nd }}$ group $(115.2 \pm 0.01)$, while the these values at 30days post-the serum Abs titers in $1^{\text {st }}$ group $(665.6 \pm 153.61)$ was higher than in $2^{\text {nd }}$ group (256.0 \pm 0.01$)$ (table: 2 ).

Table: 2.values serum Ab titers at 14 and 30 days post-immunized animals

\begin{tabular}{|c|l|c|c|}
\hline Group & Group & $\begin{array}{c}\text { 4weeksmean } \\
\pm S E\end{array}$ & $\begin{array}{c}8 \text { weeksmean } \\
\text { SE }\end{array}$ \\
\hline 1 & $\begin{array}{l}\text { Pasturell } \\
a \text { vaccine }\end{array}$ & $\begin{array}{c}307.20 \pm 86.8 \\
2 \\
\mathrm{bB}\end{array}$ & $\begin{array}{c}665.6 \pm 153.61 \\
\mathrm{Ba}\end{array}$ \\
\hline 2 & $\begin{array}{l}\text { diazepam } \\
+ \text { pasturell } \\
a \text { vaccine }\end{array}$ & $\begin{array}{c}115.2 \pm 0.01 \\
\mathrm{Ad}\end{array}$ & $\begin{array}{c}256.0 \pm 0.01 \\
\mathrm{Bd}\end{array}$ \\
\hline
\end{tabular}

L.S.D $=490.70$

The current study showed that the mean values of skin thickness in immunized animals with p.multucida (bacterin)was higher than those value in immunized animals treatment with diazepam, these result may be indicated that the diazepam depressed the cell mediated immune response with reduction in delayed type hypersensitivity (DTH) which considered one arm of CMI that mediated by CD4+Tcells and CD8+Tcells cytokine production(11).also these observation may be supported idea that diazepam have immunosuppression effects. Also our investigation was in agreement with (12), who reported that the diazepam decrease in macrophage spreading and phagocytosis was 
reported as a result of pre- and postnatal diazepam treatment in rats (13), also immunosuppress may result from inhibitory for the phagocytic functions and the antibody synthesis(14) who said diazepam was found to depress both primary antibody and delayed-type hypersensitivity responses in normal mice treated with diazepam is (15).The lower values of DTH reaction in immunized animals treated with diazepam as comparing with only immunized animals may be due to diazepam type binding in sites benzodiazepine receptors (PBR) in all endocrine steroid genic tissues, organs and cells of the immune system, such as macrophages and lymphocytes. Thus, the PBR may be a possible primary target for the immunotoxicity effects of BDZ (16).also immune toxic effects might be related to cortisol production. The present finding showed that the Abs titer in general, were high at day 60 as comparing with those values at 30 days post-immunization ,these results may be due to exposure the animals to posture dose of antigen at two weeks post-first dose which lead to stimulate the secondary immune response and the values of immune response were high in secondary immune responses as comparing with primary immune response (17), also these result may be indicated that diazepam have toxic effects on humeral immune response. Our results are in accordance with those of(17) who stated that many benzodiazepines induced prolonged impairment of cellular immune functions in experimental animals after chronic low-dosage administration. It has been substantiated that stressful stimuli in man as well as in animals lead to suppression of the humeral and cellular components of the immune system. The central nervous system is known to be involved in the regulation of stress-induced immune responsiveness (17)and administration ofbenzodiazepine with inhibition of IL-2. (17) Found that exposure to low doses of BDZ resulted in long-lasting reduction of TNF-alpha, IL-1, IL-6, IL-2 diazepam induced severe inhibitory effects on the proliferative responses of both B- and T-cells.

\section{Histopathological diazepam:}

At4weeks post-treated with diazepam

Brain: the main lesions in the brain of animals treated with diazepam were increase number of astrocytes (fig.1)
Liver: There is inflammatory cells infiltration particularly neutrophil in dilated sinusoid (fig.2) in other section large multiple granulomatous lesion consist form aggregation mononuclear particularly macrophages and lymphocyte scatter in the liver parenchyma and around congested blood vessels in addition necrosis of hepatocyte (fig.3).

Kidney: main pathological lesion characterized congestion of blood vessels (fig.4).

Spleen: Spleen showed precipitate protinicious materials in red pulp wall as well as congestion blood vessels, edema and depletion of lymphocytes in the white pulp (fig.5).

\section{At 8 weeks post- treated with diazepam:}

Brain: Microscopic section revealed mononuclear cells aggregate around blood vessels in brain parenchyma together with edema around neuron (fig.6).

Kidney; Microscopic section revealed fibrous connective tissue around blood vessels and renal tubules that showed cellular degeneration characterized by enlargement of renal epithelial cells and vacuolar degeneration. also there is sloughing of the epithelial lining cells of renal(fig.7).

Spleen: the pathological examination of the spleen showed congestion blood vessels with mononuclear cells in their lumen and depletion of white pulp as well as proliferation of megakaryocytes (fig.8).

\section{Immunized animals at 4 weeks treated with} diazepam:

Brain: No clear lesions were seen in the brain (fig.9).

Liver: aggregation mononuclear cells around central vein in addition to proliferation of kupffer cells (fig.10).

Kidney: No clear lesions were seen in the kidney.

\section{8 weeks post- treated with diazepam}

Liver: main lesion characterized in liver mice treated by diazepam with immunized by aggregation mononuclear cells around bile duct and portal vein (fig.11).

No clear lesions were seen in the kidney (fig.12), and brain. 


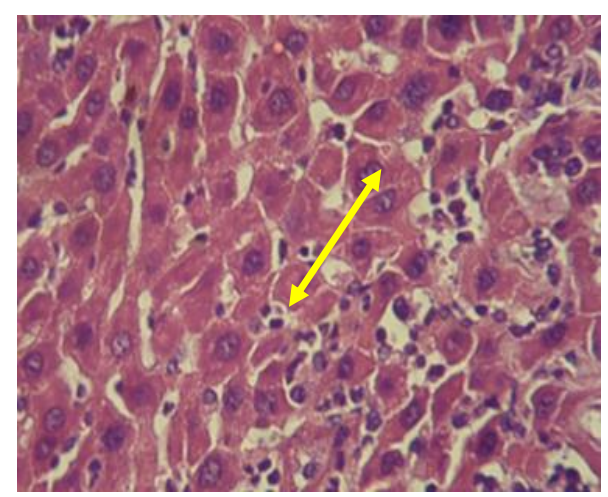

Fig:1 Histopathological section in brain of mouse treated with diazepam at (4)weeks shows focal microglial cells proliferation and perineuronal congestion and edema arrow (H\&E stain 40X).

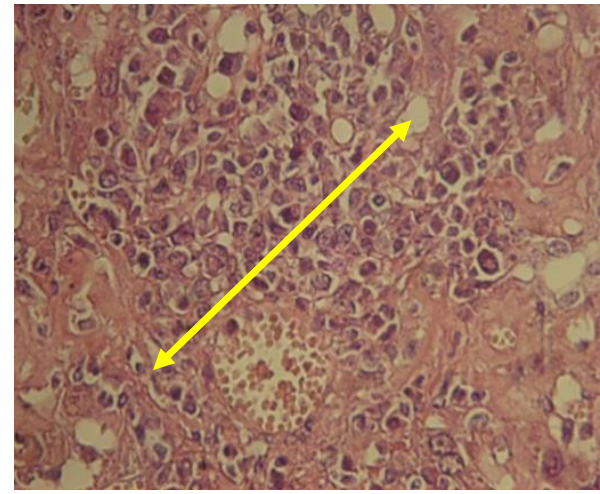

Fig:3 Histopathological section in liver of mouse treated with diazepam at (4)weeks shows large multiple granulomatous lesion and around congested blood vessels in addition to necrosis of hepatocytes arrow (H\&E stain 40X).

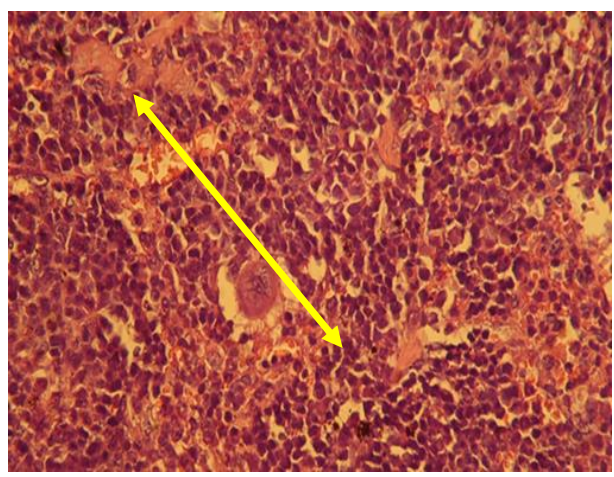

Fig: 5 Histopathological section in spleen of mouse treated with diazepam at (4)weeks shows precipitate proteinaceous substance in red pulp wall as well as congestion blood vessels, edema .also depletion lymphocytes which left space in white pulp arrow (H\&E stain 40X) (H\&E stain 40X).

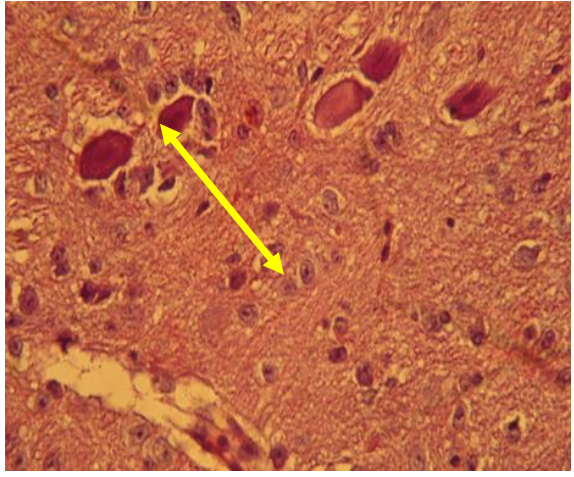

Fig:2 Histopathological section in liver of mouse treated with diazepam at (4)weeks shows inflammatory cells infiltration particularly neutrophil in the dilated sinusoid and single necrosis of hepatocytes arrow (H\&E stain

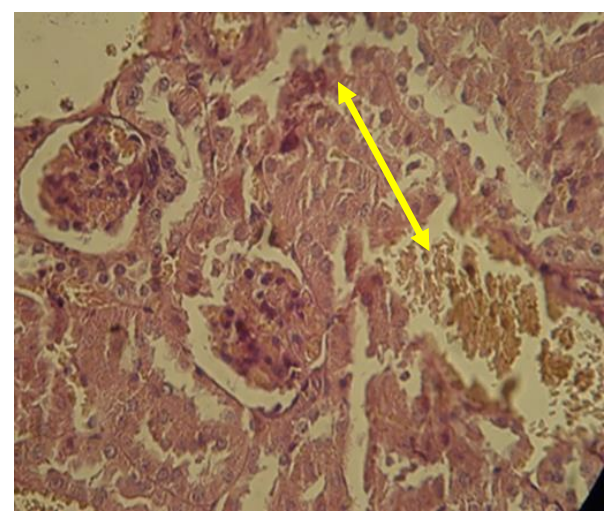

Fig:4 Histopathological section in kidney of mouse treated with diazepam at (4)weeks shows congestion blood vessels and RBCS in the lumen renal tubule arrow (H\&E stain 40X)

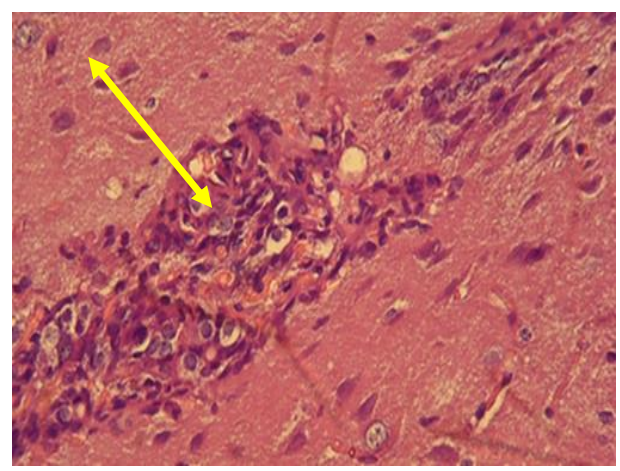

Fig:6 Histopathological section in brain of mouse treated with diazepam at (8)weeks shows mononuclear cells aggregate around blood vessels in brain parenchyma together with edema around neuron arrrow ( H\&E stain $40 \mathrm{X})$ 


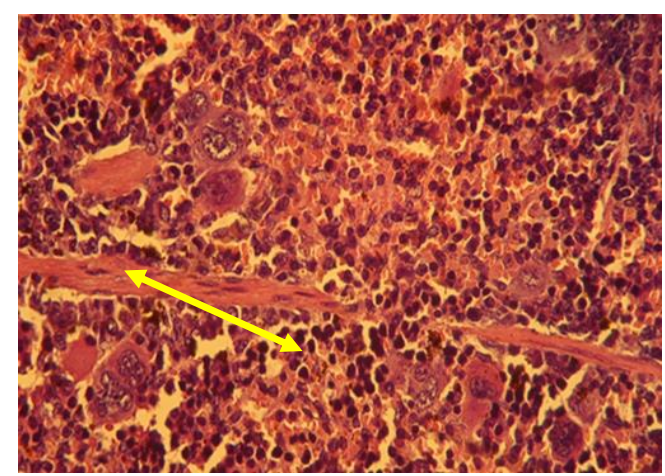

Fig:7 Histopathological section in kidney of mouse treated with diazepam at (8)weeks shows fibrous connective tissue proliferation around blood vessels and renal tubule with mononuclear cells infiltration, as well as vacuolar degeneration of epithelial lining cell of renal tubules arrow ( H\&E stain 40X)

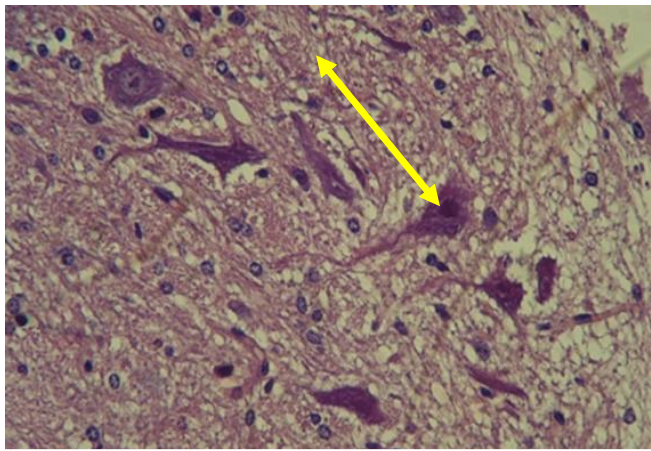

Fig: 9 Histopathological section in brain of immunized mouse treated with diazepam at (4)weeks shows no clear lesions in the brain at 30 days except perineuronal edema post treated arrow (H\&E stain 40X).

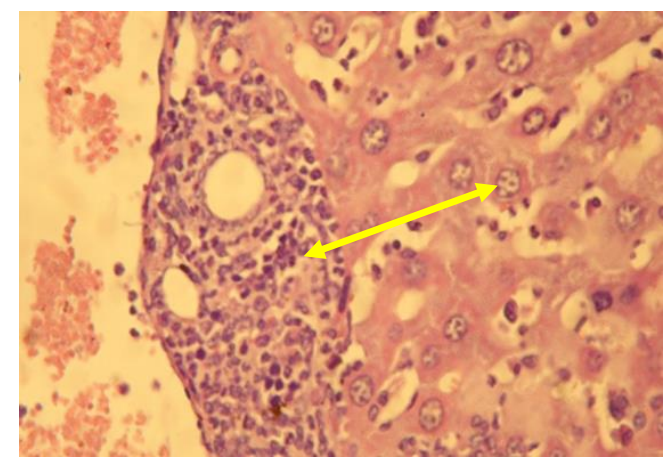

Fig11 Histopathological section in liver of mouse immunized with diazepam at (8)weeks shows aggregation mononuclear cells around bile duct and portal vein arrrow (H\&E stain 40X).

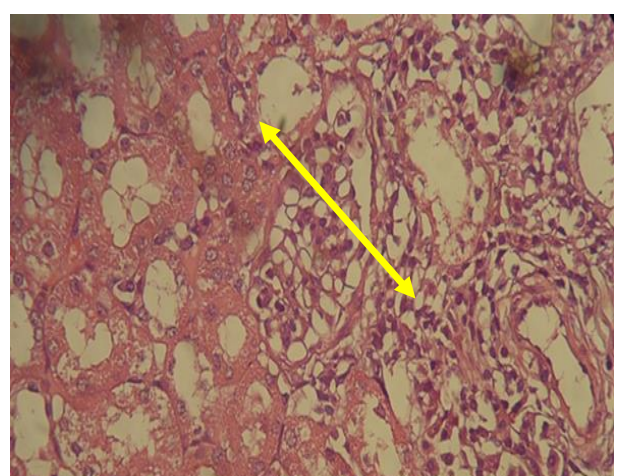

Fig:8 Histopathological section in spleen of mouse treated with diazepam at (8)weeks shows congestion red pulp and proliferation megakaryocytes and depletion of lemphoid tissues of white pulp arrow (H\&E stain 40X)

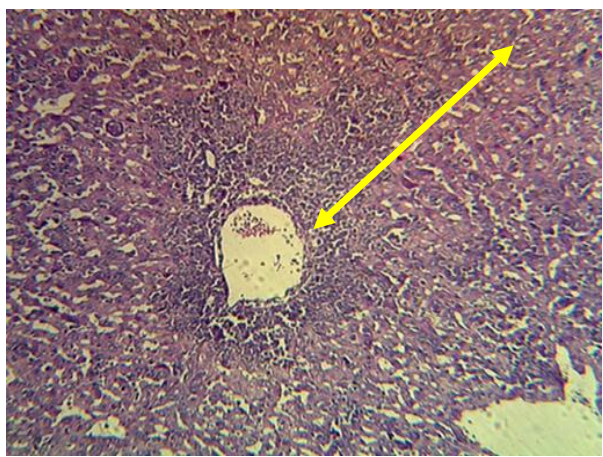

Fig:10 Histological section in liver of immunized mouse treated with diazepam at (4)weeks shows aggregation mononuclear cells around central vein in addition to proliferation of kupffer cells arrrow . (H\&E stain 40X)

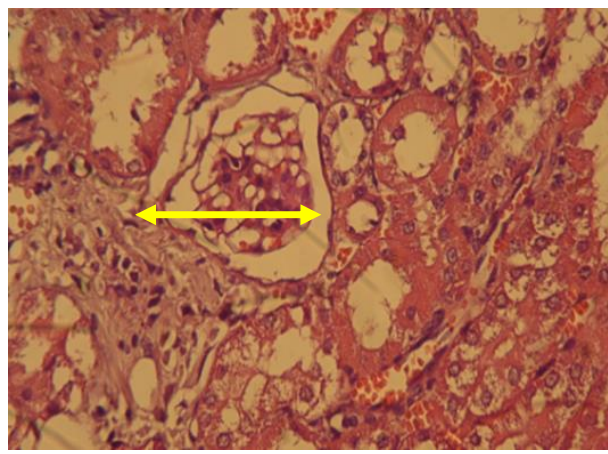

Fig:12 Histopathological section in kidney of mouse treated with diazepam and immunized at (8)weeks shows dilated of bowman capsule and proliferation fibrous connective tissues between renal tubules and around glomerular infiltrated with mononuclear cells arrrow . (H\&E stain 40X) 


\section{Discussion}

Main pathological lesion in the liver may be due to drug toxicant these results that agreed with (18) they reported that toxicity in liver characterized by the presence of hepatic cells undergo necrosis and others undergo degenerative changes and it appeared as a constant feature of all examined sections and that because of the accumulative ability of diazepam these results similar to that noticed by (19).Our result finding seen in the spleen showed protienaceous materials in red pulp as well as congestion blood vessels these results may be the spleen is considered one of the lymphoid tissue play an important role in the immune system which affected with sedative drugs lead immune suppression this agrees with (20)who found Lymphocytic depletion was noticed in both red and white pulp of the spleen in rats treated with diazepam $(0.1 \mathrm{mg})$ daily for 4 weeks. Our result finding seen in the brain of animals treated with diazepam were proliferation focal microglial cells also microscopic section revealed mononuclear cells aggregate around blood vessels in brain parenchyma these results may be attributed to the toxic effect of diazepam overdose causes CNS and respiratory depression which may lead to coma and death. Experimental data show that acute administration of high doses of diazepam results in a cascade of oxidative changes and significantly diminishes cell antioxidant defense, especially the intracellular levels of reduced glutathione (21). ,also ( 22) prenatal treatment with benzodiazepines affects the development of the immune system.in addition to, edema may be due to a breakdown of tight endothelial junctions which make up the blood-brain barrier (BBB) (23) also agreement with (24) referred that the BBB has a very important function in maintaining the fluid environment of nervous

\section{References}

1. Rusli M. befor,during and after benzodiazepine discontinuation. National Library of Medicine.. Retrieved 2006-03-11.

2. Nadia C, (2006).benzodiazepin dependence, National Library of Medicine.. Retrieved 2006-0310.MeSH

3. Riss, J.Cloyd,J.;Gates, J.Collins,S. (2008). "Benzodiazepinesinepilepsy: pharmacology and pharmacokinetics" Scand 118 (2): 69-86.

4. Papadopoulos V, Baraldi M, Guilarte TR, Knudsen $\mathrm{TB}$, Lacapère JJ, Lindemann $\mathrm{P},(2006)$ Translocator protein $(18 \mathrm{kDa})$ : new nomenclature for the peripheral-type benzodiazepine receptor based on its structure and molecular function. TrendsPharmacol Sci;27(8):402-9. system. Our result finding seen main pathological lesion characterized vacuolar degeneration in the glomerular tuft with dilatation in bowman space all these lesion may be accumulate main active metabolite of diazepam is called desmethyl diazepam in Kidneys which consider important excretory organ, which, along with the liver, also accumulate toxicants these agreement with(25).The lesions in the organs in immunized animals are mild lesions than organs animals' toxicity by benzodiazepine. This result may indicate the vaccine stimulate the immune system that this lead to activation immune cells that Contribute in protective the body from effects the diazepam this suggest Explains as follows the immunize ability of outer membrane proteins which activated $\mathrm{CD} 4 \mathrm{~T}$-cell in turn liberate lymphokines such as IL-4,IL-6 for B-cells and IL-2 for T-cells also INF- $\alpha$ FOR macrophages and all lymphokines, and the activated immune cells play a role in produce highly production against infection (26). Also the cytokine Contribute in repair tissue damage and supported this idea Cytokines are critical controllers of cell, and hence tissue, growth, migration, development and differentiation. The family includes the inflammatory cytokines such as the interleukins and interferon's, growth factors such as epidermal and hepatocyte growth factor and chemokine's such as the macrophage inflammatory proteins, MIP-1a and MIP-1b. They do not include the peptide and steroid hormones of the endocrine system. Cytokines have important roles in chemically induced tissue damage repair, in cancer development and progression, (27), the complex relationships that occur between tissues and drugs, and subsequently between cytokines and the tissue responses that modulate the therapies to which drugs are applied (28); (29).

5. de LimaM. I. P., and, CarvalhoS. C. P.,(2010)Investigating annual and monthly trends in precipitation structure: DE Lima CB, Sakai M, Latorre AO, Moreau RL, Palermo-Neto J. Effects of different doses and schedules of diazepam treatment on lymphocyte parameters in rats. Int Immunopharmacol.;10:1335-1343. [PubMed]

6. Michael RusliMD, WilliamMD, SpiveyH, Hugh BonnerMD, Robert M McNamaraMD,(1985) Endotracheal diazepam: Absorption and pulmonary pathologic effects, $\mathrm{PhD}$ Claire $\mathrm{M}$ Lathers ,Received 17 September 2003; accepted 11 November 20o3 .J ClinPathol. 38(9): 985-988.

7. Hriscu,SH; Yao YJ, Lo DS. (2002). "A survey of buprenorphine related deaths in Singapore". Forensic Sci Int. 162 (1-3): 80-6. doi:10.1016/j.forsciint03.037. PMID 16879940. 
8. Lappin, M.R.,(2001). Feline Internal Medicine Secrets. 4th Edn.,Elsevier Health Sciences, Philadelphia, ISBN-10: 1560534613, pp: 479.

9. International Union of Pure and Applied Chemistry (2005). Nomenclature of Inorganic Chemistry (IUPAC Recommendations

10. Drury RAB and Wallington EA.(1980) General staining procedures in carletons Histological Technique. 4thEd, Oxford, Oxford University press.,pp $114-37$.

11. Descotes J (1988). Immunotoxicology of Drugs and Chemicals. Elsevier, Amster-dam, New York, 120-148

12. Schlumpf M, Parmar R, Ramseier HR\&Lichtensteiger W (1990). Prenatal benzodiazepineimmunodepression: possible involvement of a peripheral benzodiaz-epine site. Developmental Pharmacologyand Therapeutics, 15: $178-185$

13. Adams DO (1974). The structure of mon-onuclear phagocytes differentiating invivo. 1. Sequential fine and histologicstudies of the effect of Bacillus Calmette-Guerin (BCG). American Journal of Pathology, 76: 17-48

14. Massoco CO \& Palermo-Neto J (1999)Diazepam effects on peritoneal macro-phage activity and corticosteroneserumlevels in Balb/C mice. Life Sciences(inpress)

15. Almawi WY, Beyhum HN, Rahme AA\&Rieder MJ (1996). Regulation of cytokineand cytokine receptor expression by glu-cocorticoids. Journal of Leukocyte Biol-ogy, 60: 563-572

16. Abbas AK, Lichtman AH \&Pober JS ( 1994)Immunity.In: Abbas AK, Lichtman AH \&Pober JS (Editor)Cellular and Molecular Immunology. $2^{\text {nd }}$ edn. W.B. Saunders, Philadelphia, 320-333

17. Kalashnikov SV, Kalashnikova EA, Kokarovtseva SN. (2002). Immunomodulat-ing effects of tofizopam (Grandaxin) and diazepam cinvitro.Mediators In-flamm 11:53-59
18. Kalender, Y., Yel,M. and. KalenderS, (2005). Doxorubicin hepatotoxicity and hepatic free radical metabolism in rats. The effects of diazepam and catechin. Toxicology, 209: 39-45. PMID: 15725512

19. Schlumpf M, Parmar R \& Schreiber A ( 1994)Hepatotoxicity as targets for developmental effects of ben-zodiazepines: a review of recent studies.Developmental Pharmacology and Therapeutics, 18: 145-158

20. BartolomucciA.( 2007). Social stressimmune functions and disease in rodents. FrontNeuroendocrinol;28:28-49

21. Hodges, R. D. (1974). The Histology of the Fowl. Academic Press, London, UK

22. McEwen, B. S. (2000). The neurobiology of stress: From serendipity to clinical relevance. Brain Res. 886:172-189

23. Anderson, G.D. andMiller. J.W. (2002) Benzodiazepines; Chemistry, Biotransformationand Pharmacokinetics, in Antiepileptic Drugs, R.H. Levy, et al., Editors., Lippincott Williams \& Wilkins: Philadelphia. p. 187-206.

24. Wermeling, D.P.(2009) Intranasal delivery of antiepilepticmedications for treatment ofseizures. Neurotherapeutics,. 6(2): p. 352-8.

25. Wallace, K.; Burt, A.D. and Wright, M.C.(2008). Liver fibrosis. Biochem J.,411:1-18.

26. Khan, A. (2008). Lead Poisoning. J. Toxicol.; 15: 55-61.

27. Robbins S. and Cotran H.(1999) Pathologic Basis of Disease (7th ed.). p. 101. ISBN 0-8089-2302-1.

28. Descotes J (1988). Immunotoxicology of Drugs and Chemicals. Elsevier, Amster-dam, New York, 120-148.

29. Baba, T. (1977). Immunogenic activity of a ribosomal fraction obtained frompasteurella multocida. Infect. Immun. 15: 1-6. 